\title{
Mid-Term Results of Revascularization of the Left Coronary Artery Territory Using in Situ Skeletonized Bilateral Internal Mammary Arteries
}

\author{
IBRAHIM M. YASSIN, M.D. ${ }^{\mathbf{1}}{ }^{\mathbf{2}}$; FAROUK M. OUEIDA, M.D. ${ }^{\mathbf{2}}$; AZZA A. ZIDAN, M.D. ${ }^{\mathbf{3}}, \mathbf{4}^{\mathbf{4}}$; \\ MUSTAFA AL-REFAEI, M.D. ${ }^{\mathbf{5}}$ and KHALED A. ESKANDER, M.D. ${ }^{\mathbf{2}}$ \\ The Department of Cardiothoracic Surgery, Faculty of Medicine, Tanta University, Tanta, Egypt ${ }^{1}$ and \\ Saud Al-Babtain Cardiac Center (SBCC), Dammam, $K S A^{2}$, The Department of Nuclear Medicine \& Radio-Isotopes, \\ Cairo University, Cairo, Egypt ${ }^{3}$, The Department of Nuclear Medicine, SBCC, Dammam, $\mathrm{KSA}^{4}$ and \\ The Department of Cardiology, SBCC, Dammam, $K S A^{5}$
}

\begin{abstract}
Background: In Situ Skeletonized Bilateral Internal Mammary Arteries (BIMA) grafting to the left coronary artery can be used in almost all surgical revascularization patients. We sought to evaluate our early and mid-term patency rate of both arteries to different targets of the left coronary artery territory.
\end{abstract}

Aim of Study: Assess the early and mid-term outcome of using the In Situ BIMA to revascularize the left coronary artery territory and the difference in the outcome between Left Internal Mammary Artery (LIMA) and Right Internal Mammary Artery (RIMA )grafting to the Left Anterior Descending coronary artery (LAD) as a main target for ischaemic patients scheduled for CABG. We evaluated this technique using the BIMA as skeletonized conduits for technical issues and on beating heart to standardize the methodology.

Patients and Methods: Retrospective data collection for two groups of consecutive patients from Jan. 2012 to Jan. 2016 with revascularization to two or more sites in the territory of left coronary artery and In situ BIMA were used. Arrangement of the bilateral IMAs is usually decided according to the coronary anatomy, quality and flow of the grafts. (GroupI) (100 patients), LIMA was used to supply the LAD and (Group II) (33 patients), RIMA was used to supply the LAD. Direct coronary angiography was done for post-operative symptomatic patients in both groups $(8 / 100)(8 \%)$ and $(3 / 33)(9 \%)(n s)$ respectively. Myocardial Perfusion Imaging (MPI) was done to the rest of both groups after written consents.

Results: There were no differences in the main pre operative demographics. No significant intraoperative difference between the LIMA and RIMA concerning the diameter, wall thickness and the occurrence rates of atherosclerosis. The average total numbers of anastomoses and bilateral IMA anastomoses per patient were (3.2 \pm 0.9$)$ and $(2.6 \pm 0.6)$, respectively. Significant difference between both groups for the number of BIMA anastomoses $(2.2 \pm 0.6$ vs. $2.7 \pm 0.8)(p<0.05)$

Correspondence to: Dr. Ibrahim M. Yassin, E-Mail: yassinimkh@yahoo.com
There were no hospital mortality and no significant difference regarding major cardiac events or sternal wound infection. The patencies to the LAD were (94/100) $(94 \%)$ and (31/33) (93\%) $(p=0.324)$, and the patencies to other than the LAD were $(96 / 100)(96 \%)$ and $(31 / 33)(93 \%)(p=0.195)$, respectively after a mean follow-up period of ( $42 \pm 34$ months).

Conclusions: In situ skeletonized bilateral IMA grafting for revascularization of the territory of the left coronary artery is feasible and can be used routinely in all patients with excellent results. Arrangement of bilateral IMAs did not affect the mid-term outcome.

Key Words: Coronary artery bypass grafting - Bilateral skeletonized internal mammary arteries.

\section{Introduction}

SAPHENOUS vein graft atherosclerosis continues to be the major cause of Coronary Artery Bypass Grafting (CABG) late failure [1].

Internal Mammary Artery (IMA) is the graft of choice for revascularization of coronary arteries in ischemic cardiac patients. The left one (LIMA), had the superiority overtime to revascularize the Left Coronary Artery (LCA) territory mainly the Left Anterior Descending (LAD) owing to its better anatomical orientation.

Better long-term outcomes have been demonstrated with bilateral IMA grafting compared to single IMA graft [2-5]

Skeletonization is an advanced technique of graft harvesting for Coronary Artery Bypass Grafting (CABG), and while it requires meticulous attention, it has many advantages. Some of many are, skeletonization of Internal Mamary Artery 
(IMA) can minimize sternal ischemia and lower the risk of mediastinitis, and is longer and larger and better quality than pedicled IMA. Since the length and flexibility of ITAs are increased if they are harvested with a skeletonized technique, some reports have described the use of such grafts for multiple grafting [6-9]

However, there is still some reluctance to use bilateral IMAs because of some factors which are mainly, the technical difficulty, lack of experience and familiarity, the prolonged operation time and increased chance of sternal infection. These factors can be eliminated with more practice, bypassing the learning curve problems, Skeletonization of both IMAs, sequential anastomosis to more than one target using the same conduit and using IMAs as in situ conduits. Long-term benefits may be achieved when in situ bilateral IMAs are used for left-side myocardial revas-cularization [7].

Currently, in situ skeletonization of BIMAs accounts for approximately $80 \%$ of our isolated $\mathrm{CABG}$ operations in our center, whatever the technique will be used whether OPCAB, on pump beating or conventional CABG. Since the longterm results of bilateral IMAs used for left coronary artery has been proved to be better than that used for Right Coronary Artery (RCA).

\section{Patients and Methods}

Retrospective data collection (medical records, data base informations) in Saud Al-Babtin Cardiac Center SBCC, Al-Dammam, KSA for the study group of $\mathrm{CABG}$ patients.

This study was approved by our Institutional Review Board (IRB), and informed consent was obtained from all patients with respect to the surgical method and post-operative angiography.

The study population included: Two groups of consecutive patients from Jan. 2012 to Jan. 2016 with evidence of indicated revascularization to two or more sites in the territory of left coronary artery and in situ BIMA were used and operated on beating heart. Patients with single IMA, usage of one of the IMAs as free graft, usage of RIMA to the RCA, patients operated with cardioplegic arrest are excluded as well as those who refused to do followup graft patency evaluation.

The study population were categorized according to the IMA supplying the LAD. (Group I) (100 patients), LIMA was used to supply the LAD \pm other target vessel and (Group II) (33 patients),
RIMA was used to supply the LAD \pm other target vessel.

Direct coronary angiography was done for postoperative symptomatic patients in both groups $(8 / 100)(8 \%)$ and $(3 / 33)(9 \%)$ (NS) respectively. MPI or CT coranary angiography was done in $(92 / 100)(92 \%)$ and (30/33) (91\%) respectively and according to the patient preference for the purpose of the study.

CABG strategy was to bypass all significant stenosis (a diameter reduction of at least 70\%) in all coronary vessels larger than $1 \mathrm{~mm}$ in diameter. Arrangement of the bilateral IMAs is usually decided according to the coronary anatomy, size/ degree of stenosis of the grafted vessels, and quality/flow of the grafts. In most of the cases, BIMAs are of good quality and flow and appropriate length, LIMA is directed to supply the LAD \pm Diag. And the RIMA to RI/OM. Basically, the larger IMA was used for the LAD. When sequential grafting is necessary in the $\mathrm{Cx}$, the longer IMA will be used for this region. Heparin was administered after all grafts were harvested.

\section{Surgical technique:}

Median sternotomy was performed in all patients. A deep pericardial stay suture was used in almost all cases as a routine, and a commercially available heart stabilizer was applied to the heart (Octopus, Medtronic Inc., Minnea-polis, MN). A bloodless field was obtained using an appropriate size intracoronary shunt and $\mathrm{CO} 2$ blower. All anastomoses were performed with an 8-0 polypropylene running suture. When the RIMA was anastomosed to the $\mathrm{Cx}$, it was routed in front of the outflow great vessels and never through the transverse sinus avoiding any kink or twist. When sequential grafting is constructed, diamond shaped side-to-side anastomosis or parallel according to the anatomy of the grafted vessels but the terminal anastomosis is always parallel. When the RIMA was anastomosed to the LAD, it was directed anterior to the aorta. When possible, the RIMA was wrapped in thymic tissue and covered with mediastinal fat to prevent injury at reopening.

Early follow-up was evaluated during the hospital stay. Immediate post-operative and before closure of the sternum, the grafts are being evaluated with flowmeter, clinical close follow-up of the daily lab. Work and ECG to detect perioperative Myocardial Infarction (MI). Mid-term follow-up was evaluated during the period of study. Coronary angiography was done for post-operative symptomatic patients in both groups $(8 / 100)(8 \%)$ 
and $(3 / 33)(9 \%)$ respectively. MPI or CT coranary angiography was done in (92/100) $(92 \%)$ and (30/33) (91\%) respectively after formal informed consent. Patients who refused the follow-up diagnostic evaluation were excluded from the study.

Clinical and angiographic outcomes were then compared between those in whom the LIMA was grafted to the LAD and RIMA was grafted to the Cx (Group I) (100 patients) and vice versa (RIMA to LAD group). And LIMA was grafted to the $\mathrm{Cx}$ (Group II) (33 patients).

Myocardial perfusion scintigraphy (SPECT mps) was done for all patients using stress/rest separate day protocol. All patients were stressed on medication pharmacologically using Adenosine intravenously through the infusion pump in a rate of $140 \mathrm{ugm} / \mathrm{min}$ for $6 \mathrm{~min}$. (925MBq) Tc-99m tetrafosmine was injected intravenously 3 mins from starting infusion in a separate arm and then the patient was called for imaging 30min later. Semiquantitaive analysis was done using Cedars-Sinai protocol. Study is interpreted as normal whenever there is diffuse homogenous radioactivity throughout the wall of the left ventricle and no evidence of transient cavity dilatation and consistent EF in the stress and rest phases. Ischemia was interpreted whenever there is inducible perfusion mismatch in stress and rest phase images. Ischemia was scored mild, moderate or sever according to the diminished radioactivity. Area of ischemia was interpreted as small when $<10 \%$ of the myocardium is involved, moderate $10-20 \%$ is involved, large $>20 \%$. Transient cavity dilatation and stress induced drop in $\mathrm{EF}>5 \%$ is to be considered even in absence of perfusion mismatch. Fixed defect is diagnosed whenever there is fixed diminished radioactivity in stress and rest phases and it represents possible infarction with no evidence of ongoing ischemia [10].

Any patient with moderate or severe degree of perfusion mismatch was considered for Coronary Angiography (CAG) and possible interference.

\section{Statistical analysis:}

Continuous variables are reported as the mean \pm standard deviation. Continuous variables were compared using the Student's $t$-test and discrete variables were compared using the $\chi^{2}$-test or Fisher's exact test. Differences were considered statistically significant at $p<0.05$. The collected data were organized, tabulated and statistically analyzed using SPSS software statistical computer package Version 13.

\section{Results}

There were no differences in the main preoperative demographics (Table 2).

No significant intraoperative difference between the LIMA and RIMA concerning the diameter, wall thickness and the occurrence rates of atherosclerosis. The average total numbers of anastomoses and bilateral IMA anastomoses per patient were (3.2 \pm $0.9)$ and (2.6 \pm 0.6$)$, respectively. Significant difference between both groups for the number of BIMA anastomoses $(2.2 \pm 0.6$ vs. $2.7 \pm 0.8)(p<0.05)$ (Table 2).

There were no hospital mortality and no significant difference regarding major cardiac events or sternal wound infection. (Table 2).

The patencies of the left and right IMAs to the LAD were (94/100) $(94 \%)$ and (31/33) $(93 \%)(p=$ $0.324)$, respectively. The patencies of the right and left IMAs to other than the LAD were $(96 / 100)$ $(96 \%)$ and $(31 / 33)(93 \%)(p=0.195)$, respectively after a mean follow-up period of ( $42 \pm 34$ months) for both groups (Table 3).

Table (1): Pre-operative clinical characteristics.

\begin{tabular}{|c|c|c|c|}
\hline & $\begin{array}{c}\text { (LIMA } \rightarrow \\
\text { LAD) } \\
(100 \text { patients) }\end{array}$ & $\begin{array}{c}\text { (RIMA } \rightarrow \\
\text { LAD) } \\
\text { (33 patients) }\end{array}$ & $\begin{array}{c}p- \\
\text { value }\end{array}$ \\
\hline - Age (years) & $(64.8 \pm 10.3)$ & $(65.4 \pm 9.3)$ & 0.53 \\
\hline - Female (\%) & $23(23 \%)$ & $8(24 \%)$ & 0.38 \\
\hline - Obesity (\%) & $28(28 \%)$ & $9(27 \%)$ & 0.67 \\
\hline - Diabetes Mellitus (DM) (\%) & $74(74 \%)$ & $24(72 \%)$ & 0.47 \\
\hline • Hypertension (\%) & $73(73 \%)$ & $25(75 \%)$ & 0.85 \\
\hline • Hypercholesterolaemia (\%) & $85(85 \%)$ & $29(87 \%)$ & 0.67 \\
\hline - Creatinine level >2mg/dl (\%) & $48(48 \%)$ & $17(51 \%)$ & 0.88 \\
\hline $\begin{array}{l}\text { - Chronic Obstructive Pulmonary } \\
\text { Disease (COPD) }(\%)\end{array}$ & $5 \quad(5 \%)$ & $1 \quad(3 \%)$ & 0.68 \\
\hline • Heavy smoker $(\%)$ & $42(42 \%)$ & $16(48 \%)$ & 0.36 \\
\hline - EURO-Score (logistic \%) (\%) & $(4.8 \pm 1.3)$ & $(5.1 \pm 1.6)$ & 0.63 \\
\hline • NYHA class & $(2.8 \pm 0.3)$ & $(2.6 \pm 0.6)$ & 0.87 \\
\hline $\begin{array}{l}\text { - Pre-operative Ejection Fraction } \\
(\text { EF\%) }\end{array}$ & $(52.8 \pm 9.3)$ & $(54.6 \pm 10.4)$ & 0.78 \\
\hline $\begin{array}{l}\text { - Three Vessels Disease (3-VD) } \\
(\%)\end{array}$ & $82(82 \%)$ & $29(87 \%)$ & 0.84 \\
\hline - Redo & $1(1 \%)$ & 0 & 0.92 \\
\hline - Emergency & $6(6 \%)$ & $3(9 \%)$ & 0.34 \\
\hline
\end{tabular}


Table (2): Intra-operative, ICU and hospital course.

\begin{tabular}{lccc}
\hline & $\begin{array}{c}(\text { LIMA } \rightarrow \\
\text { LAD })\end{array}$ & $\begin{array}{c}\text { (RIMA } \rightarrow \\
\text { LAD) } \\
(100 \text { patients })\end{array}$ & $\begin{array}{c}p- \\
\text { value }\end{array}$ \\
& $(33$ patients) & \\
\hline - Mean distal anastomoses/patient. & $(2.9 \pm 0.5)$ & $(2.8 \pm 0.6)$ & 0.35 \\
- Grafts/patient. & $(2.2 \pm 0.6)$ & $(2.7 \pm 0.8)$ & $<0.05$ \\
- Bilateral Internal Mammary Arteries anastomoses/patient. & $34(34 \%)$ & $12(36 \%)$ & 0.89 \\
- Radial Artery Graft (\%). & $32(32 \%)$ & $11(33 \%)$ & 0.79 \\
- Saphenous Venous Graft (\%). & $65(65 \%)$ & $21(63 \%)$ & 0.65 \\
- Total arterial re-vascularization (\%). & $62(62 \%)$ & $20(60 \%)$ & 0.86 \\
- Off-pump revascularization (\%). & $38(38 \%)$ & $13(40 \%)$ & 0.73 \\
- On-pump beating revascularization (\%). & $(5.5 \pm 1.6)$ & $(5.7 \pm 1.4)$ & 0.34 \\
- Total operative time (hours). & $38(38 \%)$ & $12(36 \%)$ & 0.69 \\
- Blood transfusion. & $(8.4 \pm 6.4)$ & $(9.1 \pm 5.6)$ & 0.46 \\
- ICU ventilation time (hours). & $3(3 \%)$ & $1(3 \%)$ & 0.93 \\
- Re-exploration for bleeding. & & & \\
- ICU Arrhythmias or major cardiac event (\%): & $14(14 \%)$ & $5(15 \%)$ & 0.47 \\
- Atrial Fibrillation (AF). & $2(2 \%)$ & $1(3 \%)$ & 0.38 \\
- Ventricular arrhythmias. & $1(1 \%)$ & $0(0)$ & 0.58 \\
- Peri-operative myocardial. infarction. & $2(2 \%)$ & $1(3 \%)$ & 0.68 \\
- Low Caediac Output (LCO) (\%). & $1(1 \%)$ & $0(0)$ & 0.49 \\
- IABP insertion (\%). & $2(2 \%)$ & $1(3 \%)$ & 0.59 \\
- Stroke. & $3(3 \%)$ & $1(3 \%)$ & 0.89 \\
- Prolonged ventilation (non cardiac cause). & $(1.9 \pm 1.1)$ & $(1.4 \pm 1.7)$ & 0.93 \\
- ICU stay (days). & $(9.4 \pm 7.3)$ & $(11.2 \pm 9.6)$ & 0.64 \\
- Total hospital stay (days). & $3(3 \%)$ & $1(3 \%)$ & 0.91 \\
- Sternal Wound Deheiscence (SWD). & $0(0)$ & $0(0)$ & 0.99 \\
- Mortality (cardio-respiratory related) (\%). & & & \\
\hline
\end{tabular}

Table (3): Anastomotic pattern of both groups and F/U patency.

\begin{tabular}{|c|c|c|c|c|c|}
\hline Main graft $\rightarrow$ LAD & $\begin{array}{c}\text { No. of } \\
\text { patients (\%) }\end{array}$ & $\begin{array}{c}\mathrm{F} / \mathrm{U} \text { patency } \\
(\%)\end{array}$ & $\begin{array}{l}\text { The opposite } \\
\text { graft }\end{array}$ & $\begin{array}{c}\text { No. of } \\
\text { patients (\%) }\end{array}$ & $\begin{array}{c}\mathrm{F} / \mathrm{U} \text { patency } \\
(\%)\end{array}$ \\
\hline LIMA $\rightarrow$ LAD (Group I) & $88 / 100(88.0 \%)$ & $84 / 88(96 \%)$ & $\begin{array}{l}\text { RIMA } \\
\rightarrow \mathrm{D} \\
\rightarrow \mathrm{RI} \\
\rightarrow \mathrm{RI}-\mathrm{OM} \\
\rightarrow \mathrm{OM}\end{array}$ & $\begin{array}{l}88 / 100(88 \%) \\
14 / 88(16 \%) \\
24 / 88(27 \%) \\
\\
40 / 88(45 \%)\end{array}$ & $\begin{array}{l}85 / 88(97 \%) \\
23 / 85(27 \%) \\
24 / 85(28 \%) \\
\\
38 / 85(45 \%)\end{array}$ \\
\hline LIMA $\rightarrow$ LAD-D (Group I) & $12 / 100(12.0 \%)$ & $10 / 12(83 \%)$ & $\begin{array}{l}\text { RIMA } \\
\rightarrow \text { RI } \\
\rightarrow \text { RI-OM } \\
\rightarrow \text { OM }\end{array}$ & $\begin{array}{l}12 / 100(12.0 \%) \\
5 / 12(42 \%) \\
7 / 12(58 \%)\end{array}$ & $\begin{array}{l}11 / 12(92 \%) \\
4 / 12(32 \%) \\
7 / 12(58 \%)\end{array}$ \\
\hline RIMA $\rightarrow$ LAD (Group II) & $30 / 33(91 \%)$ & 28/30 (93\%) & $\begin{array}{l}\text { LIMA } \\
\rightarrow \mathrm{D} \\
\rightarrow \mathrm{RI} \\
\rightarrow \mathrm{RI}-\mathrm{OM} \\
\rightarrow \mathrm{OM} \\
\rightarrow \mathrm{OM}-\mathrm{PL} \\
\rightarrow \mathrm{PL}\end{array}$ & $\begin{array}{l}30 / 33(91 \%) \\
4(12 \%) \\
15(46 \%) \\
6(18 \%) \\
5(15 \%)\end{array}$ & $28 / 30(93.3 \%)$ \\
\hline RIMA $\rightarrow$ LAD-D (Group II) & $3 / 33(9.0 \%)$ & $3 / 3(100 \%)$ & $\begin{array}{l}\text { LIMA } \\
\rightarrow \mathrm{RI} \\
\rightarrow \mathrm{RI}-\mathrm{OM} \\
\rightarrow \mathrm{OM} \\
\rightarrow \mathrm{OM}-\mathrm{PL} \\
\rightarrow \mathrm{PL}\end{array}$ & $\begin{array}{l}3(9 \%) \\
1(3 \%) \\
1(3 \%) \\
1(3 \%)\end{array}$ & $3 / 3(100 \%)$ \\
\hline
\end{tabular}

\section{Discussion}

The debate is still there for the ideal way to revascularize ischemic hearts either using the conventional way or beating heart as well as the selection of the conduits. In this study we evaluated the use of in situ BIMA in re-vascularization of the left coronary artery territory using beating heart surgery. Essentially, as shown in the methodology, we are usually aiming to completely revascularize all the target vessels OPCAB using the intracoronary shunts $(62 \%$ vs. $60 \%)(p=0.86)$ and only in 
case of hemodynamic instability or the high risk, we proceed for on pump beating (38\% vs. 40\%) $(p=0.73)$.

Off-pump coronary artery bypass grafting (OP$\mathrm{CAB}$ ) was shown to provide early and long-term benefits compared with conventional Coronary Artery Bypass Grafting (CABG) [11,12] . However, few studies have determined the optimum combination of OPCAB and in situ bilateral IMA grafting as shown in our current study $[\mathbf{1 2 , 1 3}]$.

Although, many of the studies was in favor of using the RIMA as a composite graft with the LIMA as Y or T, others showed that composite grafting using free IMA result in a decreased midterm survival compared to in situ bilateral ITA grafting [14].

In situ bilateral IMAs are used for left-side myocardial revascularization and was strongly recommended due to its long-term benefits [7].

Revascularization of the RCA usually deserves grafting of the PDA or the PL, and the length of the in situ RIMA is usually not enough even with skeletonization, furthermore, we believe that the patient can benefit more from this in situ arterial graft if supplies one or more targets of the left coronary artery territory. For this concept, the majority of our cases done with in situ BIMA were to the left coronary artery territory.

This concept had also been addressed long time ago by others who shown good long-term benefits and re-producibilty of its application. The length and flexibility of IMAs are increased if they are harvested with a skeletonized technique and can be used for multiple grafting $[\mathbf{7 , 8 ]}$.

In addition to providing a longer length and a better flexibility than a pedicled IMA, the skeletonized IMA was reported to have greater blood flow than that of pedicle IMA which make the grafting on beating heart easily performed [15]

Although almost all cardiac surgeons consider the LIMA being the gold standard graft to the LAD, some studies showed excellent long term patency of RIMA to LAD with no significant difference between both IMA(s) to LAD [16]

We believe that there is no differences in clinical and angiographic outcomes between grafting of the LAD with either LIMA or RIMA and based on this, we suggest that arrangement should be decided upon the quality, flow of the grafts and anatomy of the target vessels to get the maximum arterial supply to the territory of the left coronary artery using the in situ BIMA. We essentially use the larger IMA with better flow for the LAD. When sequential grafting is necessary in the $\mathrm{Cx}$ artery, and both IMAs are of good quality, LIMA can be better for this region.

The use of in situ Skeletonized BIMA for revascularization can be done in the conventional way using Cardiopulmonary Bypass (CPB) and flaccid heart as well as on beating heart. Rather than skeletonization of BIMA being demanding, the sequential anastomoses using one of (IMA) them or both (BIMA) is more demanding but being on beating heart and the heart is beating and not empty makes determining of the distance between the two anastomoses more easy and allows getting more numbers of anastomoses using the same graft [17].

In this study, there was a significant difference in the mean number of anastomoses done by the in situ skeletonized BIMA in both groups $(2.2 \pm 0.6$ vs. $2.7 \pm 0.8$ with $p<0.05)$. Using the LIMA to supply the lateral and postero-inferior wall gives the surgeon more chance to do more number of sequential anastomoses.

Actually, the main target of arrangement of both in situ BIMA in this technique is to achieve the greatest number of distal anastomoses using them. In the presence of good flow and quality of both BIMA and more than one good target on the lateral wall, we usually use the RIMA to the LAD as in (Group II) and the LIMA to these targets on the lateral wall. Also, if the quality \pm flow is better in the RIMA than in the LIMA, we use it (RIMA) to the LAD.

This strategy is very important and is a good justification to our excellent results of RIMA to LAD as shown in the results that patencies of the left and right IMAs to the LAD were (94/100) $(94 \%)$ and (31/33) (93\%) $(p=0.324)$, respectively. This means that a good IMA either LIMA or RIMA gives almost the same results to the LAD provided that we have good anastomoses and good distal runoff of the LAD.

These good results of both LIMA and RIMA when been used to supply the LAD were also achieved by others [16]

Analysis of the six patients in (Group I) and the two patients in (Group II) with post-operative LAD territory ischaemia showed that four patients in (Group I) had preoperative bad distal runoff and the other four (two in each group had anastomotic strings). 
In our strategy, we are usually harvesting the in situ skeletonized BIMA proximally up to the origin and distally with its bifurcation and even with the two bifurcating branches if the caliber of both is good. These good caliber two distal branches allowed us to supply the LAD and diagonal with this natural Y in three patients in GroupI and one patient in Group II.

The length of the in situ skeletonized BIMA specially the RIMA is another main factor determining our strategy of arrangement of both grafts. The in situ LIMA usually can cover and reach any anastomotic targeted site along the LAD and even sequentially with one of the diagonals or the Ramous Intermedius. The in situ skeletonized RIMA can also cover and reach any anastomotic targeted site along the LAD unless the heart is dilated but can never sequentially used with one of the diagonals unless having two good caliber terminal branches and the anatomy of the lesion on the diagonal is favorable as in the mentioned three cases of Group II.

The course of the RIMA to supply the lateral wall can be either in front of the aorta or retroaortic. The second although giving more length and possibility to graft two targets on the lateral wall yet being disadvantageous because of the inability to control any side-branch bleeding at the time of surgery or if the patient was re-explored for bleeding, having higher incidence of compression by the aorta and difficulty in detecting any graft kinks.

We usually use the RIMA anterior to the aorta and although the length is usually not enough to do sequential anastomoses to two targets on the lateral wall but it can serve good caliber diagonal, Ramous Intermedius and marginal arteries whether the first or even the second. We believe that determining the correct direction and course of the conduit in this way is important in preventing kinking as occurs in the second mentioned retroaortic course. This was also recommended in other studies with the same concept [16].

The procedure is demanding in general and takes more effort and relatively more time than the conventional way but on the other side, we achieved good arterial revascularization to the major or even whole of the left coronary artery territory with the least anastomotic site numbers and good long term patency.

Studies have shown that risk factors of deep SWD post-cardiac surgery include prolonged intubation, bilateral internal mammary arteries use, diabetes mellitus, post-operative bleeding, re- exploration, high Body Mass Index (BMI) and combined surgery [18].

The incidence of SWD which is a major concern in revascularization using BIMA specially in DM patients in our study was around 3\% in both groups of our study. It came in agreement with many other studies of the literature. The range of incidence of deep SWD varies $(0.4-5.1 \%)$ [19,21].

Skeletonization technique, even for both IMAs can preserve the collateral blood supply to the sternum [14,15]. Different techniques have been shown in the literature with approximate results and final conclusion of the benefit of skeletonization in preserving good part of the blood supply to the sternum and subsequent better sternal healing and low incidence of SWD or mediastinitis $[22,23]$

Limitations of the study: The study being retrospective observational, on small number of patients and mainly comparing the outcome of both in situ BIMA to different anastomotic sites to the left coronary artery territory are major limitations. The refusal of many asymptomatic patients and their cardiologists to re-evaluate their grafts with MPI or CT angio-graphy lead to exclusion of a lot of patients. The study was also limited to the on beating heart patients so, there was no control group of conventional CABG and in this way we can not guarantee the efficacy of in situ BIMA in $\mathrm{CABG}$ as a general rule.

\section{Conclusion:}

In situ skeletonized BIMA is a valid option to re-vascularize the left coronary artery territory with at least two anastomoses up to four reaching full arterial revascularization with long term excellent results. Skeletonized RIMA gives excellent long term patency to the LAD and can be an alternative to the gold standard LIMA.

Presented in: The 66th International Congress of the European Society of Cardio-Vascular and Endo-Vascular Surgery, ESCVS, May 11-14, 2017, Thessaloniki, Greece, and Published in the JCVS, June 2017.

For Citation: Yassin I.M., Oueida F.M., Zidan A.A., Al-Refaei M. and Khaled A. Eskander: Midterm results of revascularization of the left coronary artery territory using in situ skeletonized bilateral internal mammary arteries. The J. Cardio.-Vasc. Surg., J.C.V.S.; June 2017; Vol. 58; Suppl. 2-3: 60 (Abstract).

\section{Conflict of interest:}

The authors has no conflict of interest to declare. 


\section{References}

1- BUTANY J.W., DAVID T.E. and OHJA M.: Histological and morphometric analyses of early and late aortocoronary vein grafts and distal anastomoses. Can. J. Cardiol., 14 (5): 671-7, 1988.

2- OKIES J.E., PAGE U.S., BIGELOW J.C., KRAUSE A.H and SALOMON N.W.: The left internal mammary artery. Circulation, 70 (Suppl I): I213-21, 1984.

3- SONS H.J., GODERHARDT E., KUNERT J., LOSS B and BIRKS W.: Internal thoracic artery. J. Thorac. Cardiovasc. Surg., 106: 1192-5, 1993.

4- CALAFIORE A.M., Di GIAMMARCO G., TEODORI G., Di MAURO M., IACO A.L., BIVONA A., CONTINI M. and VITOLLA G.: Late results of first myocardial revascularization in multiple vessel disease: Single versus bilateral internal mammary artery with or without saphenous vein grafts. Eur. J. Cardiothorac. Surg., 26: 542-8, 2004.

5- RIZZOLI G., SCHIAVON L. and BELLINI P.: Does the use of bilateral Internal Mammary Artery (IMA) grafts provide incremental benefit relative to the use of a single IMA graft? A meta-analysis approach. Eur. J. Cardiothorac. Surg., 22: 781-6, 2002.

6- CALAFIORE A.N., Di GIAMMARCO G., LUCIANI N., MADDESTRA N., Di NARDO E. and ANGELICI R.: Composite arterial conduits for a wider arterial myocardial revascularization. Ann. Thorac. Surg., 58: 185-90, 1994.

7- SCHMIDT S.E., JONES J.W., THORNBY J.I., MILLER C.C. and BEALL A.C.: Improved survival with multiple left-sided bilateral internal thoracic arteries grafts. Ann. Thorac. Surg., 64: 9-15, 1997.

8- GUREVITCH J., PAZ Y., SHAPIRA I., MATSA M., KRAMER A., PEVNI D., LEV-RAN O., MOSHKOVITZ Y. and MOHR R.: Routine use of bilateral skeletonized internal mammary arteries for myocardial revascularization. Ann. Thorac. Surg., 68: 406-11, 1999.

9- BONACCHI M., PRIFTI E., GIUNTI G. and SALICA A.: Right Y-graft, a new surgical technique using mammary arteries for total myocardial revascularization. Ann. Thorac. Surg., 70: 820-82, 2000.

10- Imaging guidelines for nuclear cardiology procedures. J. Nucl. Cardiol., 13: e21-e171, 2006.

11- SABIK J.F., BLACKSTONE E.H., LYTLE B.W., HOUGHTALING P.L., GILLINOV A.M. and COSGROVE D.M.: Equivalent midterm outcomes after offpump and on-pump coronary surgery. J. Thorac. Cardiovasc. Surg., 127: 142-8, 2004.

12- CALAFIORE A.M., Di GIAMMARCO G., TEODORI G., IACO A.L., PANO M., CONTINI M., VITOLLA G. and Di MAURO M.: Bilateral internal thoracic artery grafting with and without cardiopulmonary bypass: Sixyear clinical outcome. J. Thorac. Cardiovasc. Surg., 130: 340-5, 2005.

13- KIM K.B., CHO K.R., CHANG W.I., LIM C., HAM B.M. and KIM Y.L.: Bilateral skeletonized internal thoracic artery graftings in off-pump coronary artery bypass: Early result of Y versus in situ grafts. Ann. Thorac. Surg., 74: S1371-6, 2002.

14- LEV-RAN O., PAZ Y., PEVNI D., KRAMER A., SHAPIRA I., LOCKER C. and MOHR R.: Bilateral internal thoracic artery grafting: Midterm results of composite versus in situ crossover graft. Ann. Thorac. Surg., 74: 704-10, 2002

15- CHOI J.B. and LEE S.Y.: Skeletonized and pedicled internal thoracic artery grafts: Effect on free flow during bypass. Ann. Thorac. Surg., 61: 909-13, 1996.

16- CHOW M.S., SIM E., ORSZULAK T.A. and SCHAFF H.V.: Patency of internal thoracic artery grafts: Comparison of right versus left and importance of vessel grafted. Circulation, 90 (Pt 2): II129-132, 1994.

17- FUKUI T., TAKANASHI S., HOSODA Y. and SUEHIRO S.: Total arterial myocardial revascularization using composite and sequential grafting with the off-pump technique. Ann. Thorac. Surg., 80: 579-85, 2005.

18- CAYCI C., RUSSO M., CHEEMA F.H., et al.: Risk analysis of deep sternal wound infections and their impact on long-term survival: A propensity analysis. Ann. Plast. Surg., 61: 294-301, 2008.

19-MOLINA J.E., NELSON E.C. and SMITH R.R.: Treatment of postoperative sternal dehiscence with mediastinitis: Twenty-four-year use of a single method. J. Thorac. Cardiovasc. Surg., 132: 782-7, 2006.

20- IMMER F.F., DURRER M., MÜHLEMANN K.S., et al.: Deep sternal wound infection after cardiac surgery: Modality of treatment and outcome. Ann. Thorac. Surg., 80: 957-61, 2005.

21- LOSANOFF J.E., RICHMAN B.W. and JONES J.W.: Disruption and infection of median sternotomy: A comprehensive review. Eur. J. Cardiothorac. Surg., 21: 8319, 2002.

22- HIGAMI T., MARUO A., YAMASHITA T., SHIDA T. and OGAWA K.: Histologic and physiologic evaluation of skeletonized internal thoracic artery harvesting with an ultrasonic scalpel. J. Thorac. Cardiovasc. Surg., 120: $1142-7,2002$.

23- PARISH M.A., ASAI T., GROSSI E.A., ESPOSITO R., GALLOWAY A.C., COLVIN S.B. and SPENCER F.C.: The effects of different techniques of internal mammary artery harvesting on sternal blood flow. J. Thorac. Cardiovasc. Surg., 104: 1303-7, 1992. 


\section{الثتائج الجراحية على الملى المتوسط لعمليات التروية الدموية

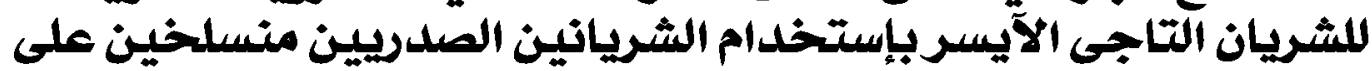

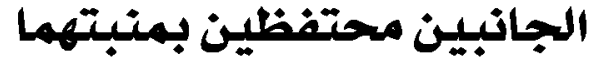

المقدمة": من الممكن جراحيا إعادة الترية الدموية الشريان التاجى الآيسر بإستخدام الثريانين المدريين منسلخين على الجانبين

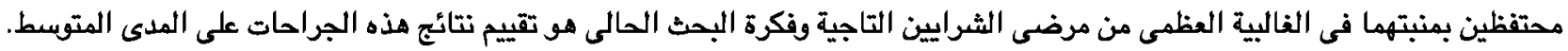

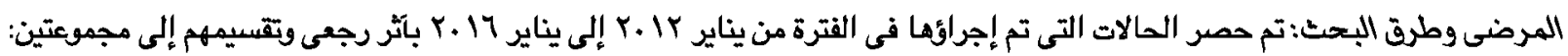

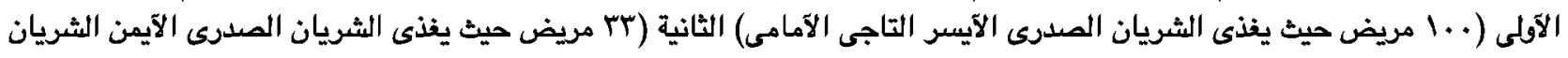

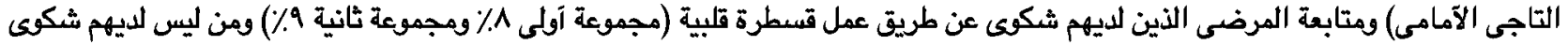

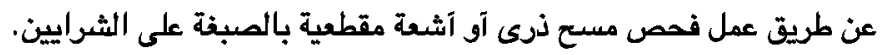

النتائج: لا يوجد فرق بين خصائص المجموعتين من النواحى الديموجرافية - لا توجد فرقق واضحة بين الشريانين المبريين الآيمن

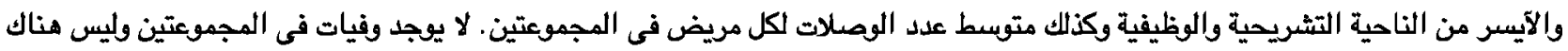

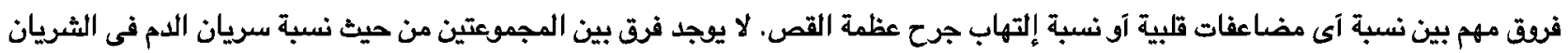

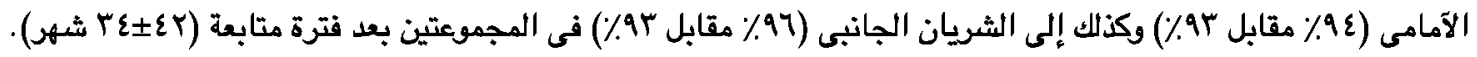
الحخلاصة: آظهر البحث آنه من الممكن وبسهولة إستخدام الثريانين الصدريين منسلخين على الجانبين محتفظين بمنبتهما في الغالبية العظمى من مرضى الشرايين التاجية وبنتائج ممتازة ودون مثاكل جانبية وبصفة روتينية. ترتيب الشريانين آثناء الجراحة لم يؤثر على النتائج 